\title{
Size estimation of circular home range from fish mark-release-(single)-recapture data: case study of a small labrid targeted by recreational fishing
}

\author{
M. Palmer*, S. Balle, D. March, J. Alós, M. Linde \\ Instituto Mediterráneo de Estudios Avanzados IMEDEA (CSIC UIB), C/ Miquel Marqués 21, 07190 Esporles (Mallorca), Spain
}

\begin{abstract}
Contrary to common belief, empirical evidence shows that a number of marine littoral fish species tend to remain in a small geographic area. Despite the growing awareness about the consequences of reduced mobility (e.g. design of marine protected areas), an accurate description of fish movement is technically difficult; thus, it is usually not considered. Mark-release-(single)-recapture (MRsR) data obtained from externally tagged fish that are returned by fishermen or recreational fishers are potentially useful for describing fish movement. The present study is a methodological contribution aimed at demonstrating a simple analytic strategy for estimating the size of the circular home range (i.e. the area where a fish spends most of the time) from MRsR data. This analytic strategy is not adequate for pelagic or large predators moving at the oceanic scale but could be suitable for some reef or littoral fish. The estimates obtained by this method are robust even if (1) the number of recaptured fish is small, (2) fishing effort or habitat suitability displays some spatial variability and (3) fish display some intra-specific variability. Based on only 32 recaptures, our data demonstrate that Coris julis (a small labrid targeted by recreational fishers) is more sedentary than previously assumed; this fish spends $95 \%$ of its time within an area $227 \mathrm{~m}$ in radius (Bayesian $95 \%$ credibility interval: 192 to $275 \mathrm{~m}$ ).
\end{abstract}

KEY WORDS: Fish movement · Home range $\cdot$ External T-bar anchor tags $\cdot$ Recreational fishing

\section{INTRODUCTION}

Connectivity processes are commonly not considered in the analysis of fish population dynamics (Botsford et al. 2009, but see Hilborn 1990, McGarvey \& Feenstra 2002, Kerwath et al. 2008, McGarvey et al. 2010); however, the life history of many marine fish includes not only a highly dispersive phase (egg-larvae), but also a juvenile-adult phase with increased swimming capability. Eggs and larvae are capable of dispersing very large distances. Accordingly, considerable effort is being devoted to understanding egg-larvae dispersal and predicting the expected spatio-temporal patterns of their destinations or the level of self-recruitment (Marshall et al. 2010). Individualbased models, coupled to hydrodynamic models, are increasingly showing the key effects of behavioral rules on fish position and how behavior is strongly linked to survival (Vikebo et al. 2007, Parada et al. 2008, Kristiansen et al. 2009).

The juvenile-adult phase in many (but not all) species creates additional connectivity over a broad range of temporal and spatial scales, from daily movement over meters to migrations over thousands of kilometers (Nagelkerken et al. 2000, Cocheret de la Morinière et al. 2002, Unsworth et al. 2007, Botsford et al. 2009). When considering only a relatively narrow temporal scale (excluding movements related to, for example, obvious day-night shifts and ontogenetic or reproductive migrations), the common null hypothesis concerning adult fish movement is that the fish move freely within relatively large patches of a suitable habitat. Empirical evidence, however, indicates that some species spend most of the time engaged in routine activi- 
ties (such as foraging and resting) within the same specific and preferred area or 'home range' (Kramer \& Chapman 1999, Crook 2004). The home range of many coral reef species is relatively small (Botsford et al. 2009). Fewer data points are available for temperate littoral fish, but interestingly, in all 7 species examined in a recent review article (Botsford et al. 2009), the maximum radius of the home range is $138 \mathrm{~m}$ (range: 32 to $138 \mathrm{~m}$ ). In an environment that is plausibly homogeneous at spatial scales larger than $138 \mathrm{~m}$, adult fish could theoretically move along larger areas than they actually do. An estimate based on environmental homogeneity alone will therefore overestimate home range.

Adult fish movement is more relevant to population dynamics when fish mortality is spatially heterogeneous. This relevance is obvious in the extreme case of areas closed to fishing (e.g. marine protected areas or MPAs). When the size of adult home range is smaller than the MPA size, the probability of movement from a low- to a high-fishing effort area is also small. Therefore, sustainability of the local population inhabiting the MPA is enhanced. The same reasoning predicts that local depletions can occur when fish home range is reduced and fishing effort is spatially clustered. The latter scenario is characteristic for some target species of recreational fishing because anglers typically cluster in small areas, and the primary motivation for selecting these areas is not always fish abundance (e.g. distance to the port; March 2008).

Thus, though there are clear reasons to consider movement in fisheries management, it is rarely done (but see references above), probably because accurate description of fish movement is technically difficult. Acoustic tracking is a recently developed approach (Voegeli et al. 2001, Parsons \& Egli 2005, Heupel et al. 2006), but it is applicable to relatively large fish only. PIT (passive integrated transponder)-tags are an interesting alternative, but they are useless for almost all littoral and reef marine fish because the distance between transmitter and receiver must be very short. Conversely, conventional external tags (typically, Tbar anchor tags) can be used in small littoral and reef marine fish. Mark-release-recapture (MRR) data have been extensively used for describing animal movement, and state-space or other models using such data have been developed to understand the movement and habitat use of a wide range of organisms (Jonsen et al. 2003, 2005, Patterson et al. 2008, Royle et al. 2009). However, typical fish-tagging programs produce mark-release-(single)-recapture data (MRsR) because they are based on the fish returned by fishermen or recreational fishers. Moreover, the conventional approach of fisheries science for describing and analyzing fish movement from MRsR data focuses on a broad geographic scale to estimate the rate of net movement (migration) between a few discrete subregions (Hilborn 1990, McGarvey \& Feenstra 2002). The movement of a specific fish within a subregion or how it could be affected by within-subregion environmental variability is not a relevant issue in this context. Conversely, the approach presented here focuses on describing individual fish movement at a relatively short temporal scale and a relatively small spatial scale. The present study is a methodological contribution aimed at demonstrating an analytic strategy for estimating the size of a circular home range using a simple movement model (biased random walk, BRW; Codling et al. 2008) and MRsR data. In addition, a number of computer simulation experiments were completed to evaluate the accuracy and precision of this method for estimating the home range size in realistic scenarios when (1) the number of recaptured fish is small, (2) fishing effort and environmental suitability display some spatial variability and (3) fish display some intra-specific variability.

\section{MATERIALS AND METHODS}

Species studied. The Mediterranean rainbow wrasse Coris julis (Labridae) is a small littoral marine fish that inhabits rocky bottoms and Posidonia oceanica seagrass beds from the shoreline up to a depth of $50 \mathrm{~m}$ (Sanchez-Delgado 1981). Its spatial distribution includes the Mediterranean Sea, the Southern Black Sea and the Northeast Atlantic (Sanchez-Delgado 1981). The diet of $C$. julis is composed of small invertebrates (polychaetes, crustaceans and mollusks) (Stergiou \& Karpouzi 2002). C. julis is protogynous and diandric, so most individuals are sequential hermaphrodites. The initial (female) and terminal (male) phases have distinct colors; however, a few individuals have these distinct color phases but remain male throughout their lifespan (Lejeune 1987, Linde \& Palmer 2008). This species seems to be sedentary (Santos et al. 2005), but there is no direct evidence to support this conclusion. In the Balearic Islands (NW Mediterranean), no catches of $C$. julis by trawling or other commercial methods have been reported (Balearic Island Government unpubl. data).This species is, however, one of the most important target species of recreational fishers (Morales-Nin et al. 2005).

Mark-release-recapture program. In total, 689 individuals of Coris julis were marked and released after capture by hook-and-line between February 2006 and May 2007. The fish were marked onboard and released at the same location where they were captured. Experimental fishing was performed at shallow depths $(<20 \mathrm{~m})$ to minimize barotraumas (and thus minimize 
post-release mortality rates; Alós 2008), and in an adequate habitat (Posidonia oceanica seagrass beds). Only fish that were hooked shallowly, in non-critical anatomical locations, were considered adequate for marking because deep-hooked individuals have reduced post-release survival rates (Alós et al. 2008, 2009). Large circle hooks were used to reduce the incidence of deep-hooking (Alós et al. 2008). Only individuals in good physical condition (i.e. those without hooking injuries or evidence of barotrauma on visual inspection 10 min after capture) were selected to be marked and released. The fish were marked with Floy T-bar anchor tags (FF-94) below the dorsal fin. The mark was $4 \mathrm{~cm}$ in length. Each mark displayed an identification number and a telephone number. Total fish length (to the nearest $\mathrm{mm}$ ), date, time, capture depth (m) and GPS position were recorded for each individual released.

All fishing was conducted at Palma Bay (Balearic Islands, NW Mediterranean; Fig. 1). Recreational fishing is very popular in this area (Morales-Nin et al. 2005). A communication program was designed and implemented to inform the recreational fishing community about the scientific reasons for the project, the study zone, and the steps to take if a tagged fish were caught. The communication program consisted of television and radio appearances, in which scientists requested the cooperation of recreational fishers; leaflet distribution; the organization of angling competitions; lectures; and a webpage. A reward was offered to fishers delivering tagged fish (a T-shirt and an entry into 2 lottery draws for fishing gear valued at 300 Euros each).
Most of the anglers not only returned the marked fish but also provided the GPS position of the recapture. In other cases (e.g. fishing from shore or competitions), it was easy to precisely determine the recapture location after an interview. In a few cases, only an imprecise description of the recapture location was available. These cases were not included in the analyses. However, the method described below assumes that reported positions and dates are accurate.

Theoretical setup. The most widely used models for describing animal movement are random walk (RW) processes (Gardiner 1990, Turchin 1998, Horne et al. 2007, Codling et al. 2008). Many different forms of RW processes have been used to describe the different types of movements encountered in different scenarios and species (reviewed by Codling et al. 2008). Simple RWs are uncorrelated (i.e. the direction of movement at a given time step is independent of the previous directions moved; the location at an specific time step depends on the location at the previous time step plus a random term) and unbiased (i.e. there is no preferred direction). Movement under such circumstances is Brownian, and the pattern produced at the population level is a standard diffusion (Codling et al. 2008). In correlated RWs, movement direction at a given time step is correlated with the previous (and successive) time steps. The outcome is a tendency to move forward (Codling et al. 2008). Biased RWs (BRWs) describe movement paths toward a given target. It is possible to develop very complex BRWs. We, however, have explored a very simple case: we describe the movement of Coris julis as a BRW in a harmonic, bidimen-

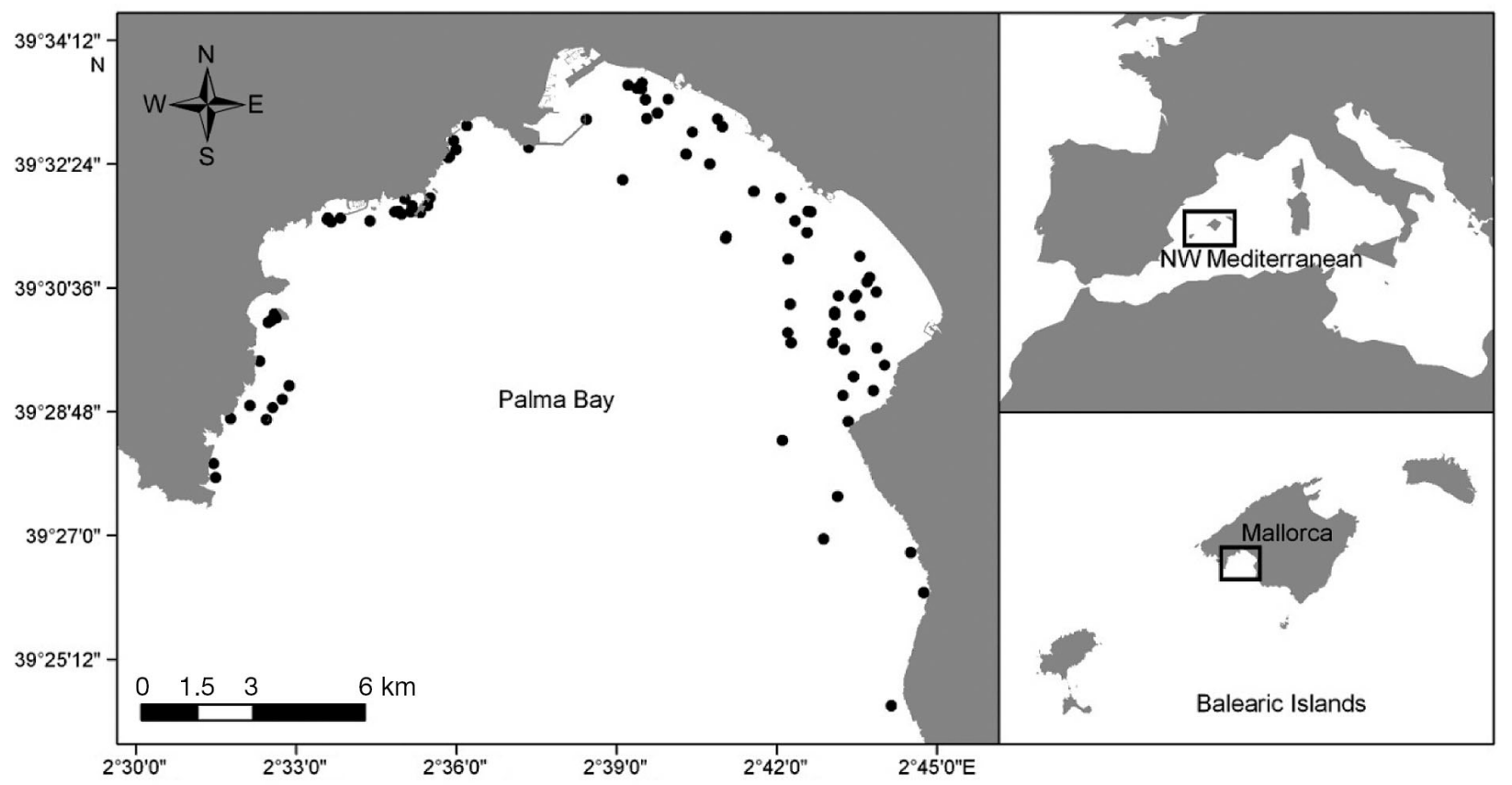

Fig. 1. Coris julis. Experimental fishing sessions $(\bullet)$ in Palma Bay where 689 individuals were captured and released 
sional potential field, the strength of which describes the extent of the home range. The rationale behind this model is that a fish moves in an essentially homogeneous environment following random stimuli, but with a tendency to remain around a specific point.

Thus, we consider that the trajectory of a fish, $r(t)=$ $(x(t), y(t))$, is described by the stochastic Langevin equation (Gardiner 1990):

$$
\dot{r}=-k r+\sqrt{\varepsilon} \xi(t)
$$

This equation yields an Ornstein-Uhlenbeck process. A fish is attracted toward the center of its home range (taken to be the origin of coordinates) by a central harmonic force of constant $k$, while it is also subjected to a random force described by a Langevin term. This term is the product of a scale factor $(\varepsilon)$ and $\xi(t)$, a 2-dimensional (2D) Gaussian variable (white noise), with a zero mean and unit variance in each dimension, and zero cross-correlation among dimensions, i.e.

$$
\begin{gathered}
\bar{\xi}_{i}(t)=0 \\
\bar{\xi}_{i}(t) \bar{\xi}_{j}\left(t^{\prime}\right)=\delta_{i j} \delta\left(t-t^{\prime}\right)
\end{gathered}
$$

The solution to Eq. (1) is:

$$
r(t)=r_{0} \mathrm{e}^{-k t}+\sqrt{\varepsilon} \int_{0}^{t} \xi\left(t^{\prime}\right) \mathrm{e}^{-k\left(t-t^{\prime}\right)} \mathrm{d} t^{\prime}
$$

where $r_{0}$ is the initial position of the fish.

The numerical approximation to the real trajectory sampled with a finite time step $\Delta t$ is given by:

$$
r_{m+1}=\mathrm{e}^{-k \Delta t}\left[r_{m}+\sqrt{\varepsilon \Delta t} N_{m}(0,1)\right]
$$

where $r_{m}$ denotes the position of the fish at time $t_{m}=$ $m \Delta t$ and $N_{m}(0,1)$ is a 2D Gaussian random variable (white noise) with zero mean and unit variance in each coordinate and zero covariance among coordinates.

The impact of the model parameters $(k$ and $\varepsilon)$ on the particle (fish) trajectories is demonstrated by comparing simulated paths of a particle moving with Eq. (5) and using different combinations of values (Fig. 2). Note that $k=0$ produces a simple isotropic random walk (Codling et al. 2008), for which the limits of the home range are undefined. The biological interpretation of $k$ and $\varepsilon$ is fully described in 'Results: Feasibility of parameter estimates', but note that (1) the size of the home range depends on the ratio $\varepsilon / \mathrm{k}$ and that (2) processes with large $\varepsilon$ value will tend to have more erratic trajectories.

Model parameterization. The application of the BRWs to the MRsR data requires an estimation of parameter values from the observed distances between mark and recapture locations.

In this case, the displacement of the fish after time $t$ is:

$$
r(t)-r_{0}=-r_{0}\left(1-\mathrm{e}^{-k t}\right)+\sqrt{\varepsilon} \int_{0}^{t} \xi\left(t^{\prime}\right) \mathrm{e}^{-k\left(t-t^{\prime}\right)} \mathrm{d} t^{\prime}
$$
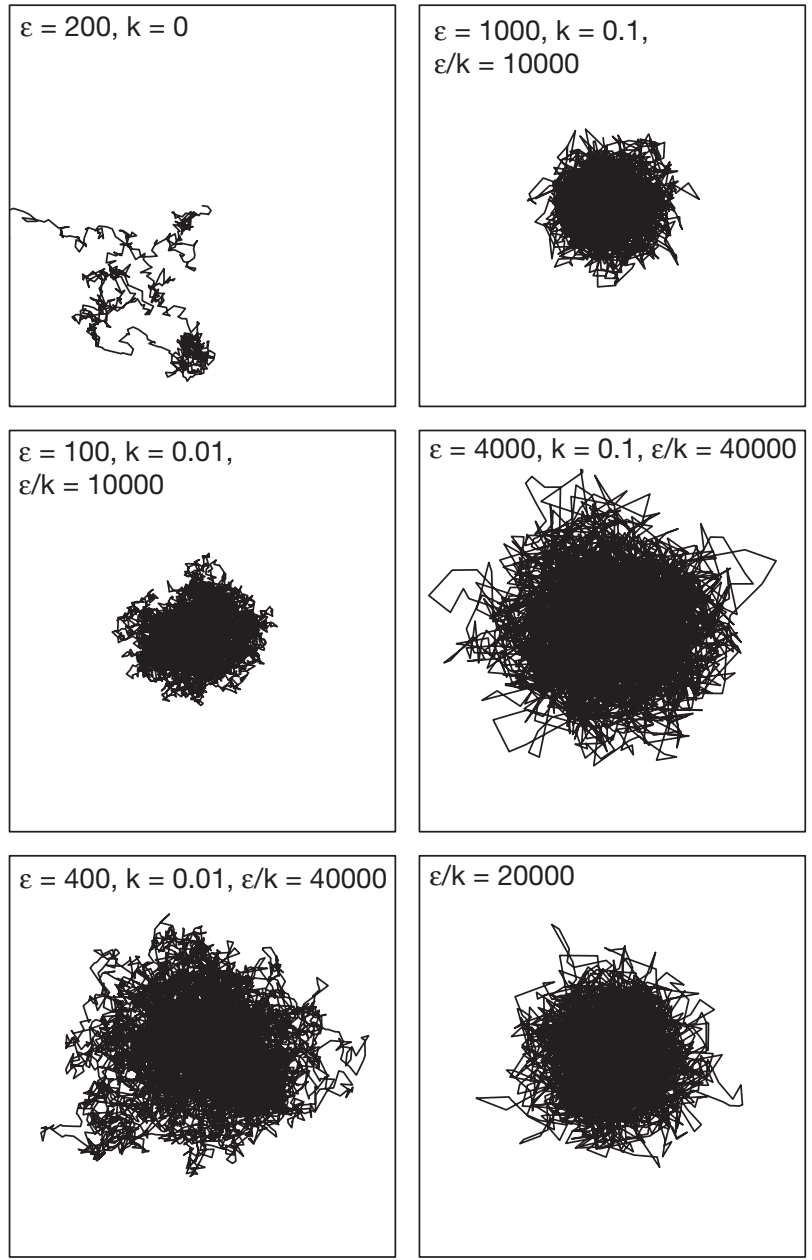

Fig. 2. Coris julis. Simulated biased random walks (BRWs) with various values for parameters $k$ and $\varepsilon$ (see Eqs. 1 to 4 ). A line connects the successive positions of a fish released at the center of the scenario map. Number of time steps and spatial scale is the same in all panels. Note that home range size seems to depend on the $\varepsilon / k$ ratio only. The lower-right panel gives an example BRW for a fish with an $\varepsilon / k$ value similar to

that estimated from the observed mark-recapture data

Thus, the traveled distance $d$ (squared) at this time is:

$$
d^{2}(t)=\left|r(t)-r_{0}\right|^{2}
$$

We can immediately determine the mean squared distance traveled:

$$
\overline{d^{2}(t)}=\left(1-\mathrm{e}^{-k t}\right)^{2} \overline{r_{0}^{2}}+\frac{\varepsilon}{k}\left(1-\mathrm{e}^{-2 k t}\right)
$$

and if we assume that $r_{0}$ corresponds to the stationary distribution of the same process, we have:

$$
\overline{d^{2}(t)}=\frac{\varepsilon}{k}\left[\left(1-\mathrm{e}^{-k t}\right)^{2}+\left(1-\mathrm{e}^{-2 k t}\right)\right]=2 \frac{\varepsilon}{k}\left(1-\mathrm{e}^{-k t}\right)
$$

This last equation tends asymptotically to $2 \varepsilon / k$ for long times, thus providing a way to estimate the size of the home range (see 'Home range size estimation'). 
The probability density function (PDF) of $d^{2}(t)$ is an exponential distribution with mean $\overline{d^{2}(t)}$ :

$$
P\left(d^{2}, t\right)=\frac{1}{\overline{d^{2}(t)}} \mathrm{e}^{-d^{2} / \overline{d^{2}(t)}}
$$

which corresponds to a bidimensional $\chi^{2}$ distribution for the particular case of the sum of 2 uncorrelated random variables of zero mean and equal variance as those describing the fish trajectory.

Note that Eq. (9) would allow us to estimate the model parameters from the squared distances between the mark and recapture locations of the same fish. In the case of MRsR, however, a given fish experiences only a single recapture. Alternatively, we might estimate the model parameters by pooling data from different recaptured individuals. This approach is justified provided that (1) all fish have almost the same values for $k$ and $\varepsilon$, and (2) the environment is essentially homogeneous. Under these assumptions, the observed $d^{2}$ values for different fish can be interpreted as independent realizations of the same process.

Knowledge of the theoretical PDF for $d^{2}$ largely simplifies the implementation of a Bayesian approach for estimating the posterior probabilities of $k$ and $\varepsilon$ given the data $\left(d^{2}{ }_{i}\right.$ and $t_{i} i$ being between 1 and $n$ returned fishes). The model was implemented and run using the BRugs library of the R-package (at www.r-project.org/) that opens OpenBugs (at http://mathstat.helsinki.fi/ openbugs/). The full script and an example data set are provided in Supplement 1 at www.int-res.com/ articles/suppl/m430p087_supp/.

Minimal prior knowledge has been assumed. Prior values for $k$ are assumed to follow a uniform distribution between 0 and $10^{5}$, while prior values for $\varepsilon / k$ are assumed to follow a uniform distribution between 0 and $10^{8}$. In addition, to evaluate the impact of prior selection, an alternative implementation was run assuming a normal $(\varepsilon / k)$ and a gamma distribution $(k)$, both with huge effective ranges.

Five Monte Carlo Markov (MCM) chains were run using randomly chosen initial values for $k$ and $\varepsilon / k$ (within a reasonable interval; see script at Supplement 1). Convergence was checked using the standard toolkit available in OpenBugs. The first 2000 iterations were discarded. The autocorrelation was also analyzed, and thinning was adopted to ensure the independence of successive values within each chain (only one out of every 10 consecutive values was kept). The number of valid iterations after convergence and thinning was 10000 .

Home range size estimation. Home range area was defined as the area within which a fish has a $95 \%$ probability of being found during a given period of time (Calenge 2006). Therefore, from the definition of the inverse cumulative distribution function for the exponential distribution, the radius of home range (HRradius) can be estimated by:

$$
\operatorname{HRradius}(p ; \lambda)=\sqrt{-\ln (1-p) / \lambda}=\sqrt{\frac{-\ln (1-0.95)}{k / \varepsilon}}
$$

Simulation experiments. We evaluated the accuracy and precision of this method for estimating the size of home range in realistic scenarios. We specifically focused on evaluating the effects of (1) the number of recaptured fish (32 observed recaptures vs. 300 simulated recaptures), (2) the existence of some spatial variability in fishing effort and (3) the existence of between-fish variability.

Simulation Expt 1 (number of recaptured fish): We simulated the trajectories of 32 fish (the number of fish returned at that time) over 1800 time units with a time step of $\Delta t=0.001$. Fish started to move from the center of the home range. Fish were assumed to be captured and marked after 300 time units (after this time, the current position is independent of the starting position). Fish moved following Eq. (5). The value of $\varepsilon / k$ was set to 20000 (close to the value estimated for the observed data; see 'Results'). The parameter $k$ was set to an arbitrary value of 0.1 . Thus, the distance from the position where fish $i(1<i<32)$ was marked and the position at time $t$ was known for any $t$ between 1 and 1800 time units.

One specific time-at-liberty $\left(t_{i}\right)$ was randomly selected (between 300 and 1800) for each of these 32 fish. The simulated data set $\left(d^{2}{ }_{i}\right.$ and $t_{i}$ for the 32 simulated fish) was then analyzed with the same procedure used to estimate the parameters for the observed data (i.e. the Bayesian approach described in 'Model parameterization' and Supplement 1).

Random selection of $t_{i}$ was performed such that the distribution of the simulated times-at-liberty emulated the distribution of the observed times-at-liberty. The expected distribution of times-at-liberty over time is given by a negative exponential (McGarvey 2009; see also the derivation in Supplement 2 at www.int-res. com/articles/suppl/m430p087_supp/). The shape of the actual distribution of $t_{i \text { observed }}$ closely follows a negative exponential (this pattern is observed because the first weeks after marking accumulated most of the recaptures) with rate $\lambda=1 /\left(\Sigma t_{\text {iobserved }} / 32\right)$, where timesat-liberty is measured in days. Thus, $t_{i \text { simulated values }}$ (one per fish) were randomly drawn from a negative exponential distribution with this $\lambda$ value.

The overall process (release of 32 fish over 1800 time units, random selection of $t_{i}$ and subsequent estimation of $k$ and $\varepsilon / k$ ) was repeated 1000 times and the estimated values ( $k$ and $\varepsilon / k$ ) were stored for comparison with the known values (i.e. those used for simulating 
the movement paths: $k=0.1$ and $\varepsilon / k=20000$ ). The same procedure was repeated simulating 300 recaptured fish instead of 32 (to compare the precision and accuracy obtained from a larger number of recaptures).

Simulation Expt 2 (spatial heterogeneity of fishing effort): This test is very important because the distance between mark and recapture may be biased when fishing effort and/or release locations are clustered. Markrelease locations can be considered randomly located within the area of Palma Bay with suitable habitat for Coris julis (Fig. 1); however, fishing effort cannot be considered strictly homogeneous. The GPS position of all fishing boats in Palma Bay was determined from more than 200 daily censuses from boats over the course of nearly 3 yr (March 2008). In the environmentally suitable area for $C$. julis, the ratio between the fishing effort experienced by the most- and least-fished locations is approximately 5:1 (March 2008). In addition, fishing effort exhibits some amount of spatial autocorrelation (March 2008). These data (strength of spatial autocorrelation and the ratio 5:1, or, conservatively, 10:1) were used to create 1000 simulated but realistic scenarios of spatially heterogeneous fishing mortality. Each of these simulated scenarios comprised $100 \times 100$ cells, each $1 \mathrm{~km}^{2}$ in size. Each of those cells is given a specific fishing mortality $F_{i}$. Random scenarios with the same amount of spatial autocorrelation, mean and variance as the observed fishing effort were produced using the RandomFields library of the R package (Schlather 2001; http://cran.r-project.org/ web/packages/RandomFields ver. 1.3.41, accessed August 2010). Full details are provided in Supplement 3 at www.int-res.com/articles/suppl/m430p087_supp/.

In each of these 1000 scenarios, $N_{0}$ fishes (689) were released. The number of release sites was the same as in the mark-recapture field experiment. Fish moved following Eq. (5) and with the same settings used in Simulation Expt 1. In addition, we recorded not only the distance from the current position to the release site but also the current position. $F_{i}$ values were obtained from the fish position at $t=i$. Note that $F$ is spatially heterogeneous. Therefore, (1) a single fish (depending on its position within the scenario) may experience different fishing mortality $\left(F_{i}\right)$ during the simulation experiment, and (2) there could be considerable differences in the fishing effort experienced by different fishes. $M$ (natural mortality) and $R$ (return rate) were considered constant. The status of every fish (i.e. fished, dead and returned) was defined at every time unit, and the probabilities associated with $F_{i}, M$ and $R$ were compared with random numbers uniformly distributed between 0 and 1). Finally, after all marked fish $\left(N_{0}\right)$ had died, we selected the returned fish and analyzed times-at-liberty $\left(t_{i}\right)$ and squared distance traveled $\left(d^{2}{ }_{i}\right)$ by the Bayesian approach described in 'Model parameterization' and Supplement 1.
Simulation Expt 3 (between-fish variability): As in Simulation Expt 1, 32 fish were released in a spatially isotropic scenario. Fish moved according the model described in Eq. (5). However, the movement parameters were allowed to change, with a coefficient of variation for the home range size similar to the one reported by March et al. (2010). Between-individual variability in home range size in a similarly-sized temperate-reef species (Serranus scriba) has recently been estimated by acoustic tracking (March et al. 2010). Despite the fact that the number of fish used in these experiments is usually small, the between-individual variability in home range size seems to be small as well $\left(1.1075 \pm 0.204 \mathrm{~km}^{2}\right)$. The ratio between mean and variance in the case of $S$. scriba is 0.18 . Thus, in our case, the $\varepsilon / k$ ratio of each simulated fish was randomly sampled from a normal distribution with a variance equal to $18 \%$ of the mean (this mean being equal to $20000 \mathrm{~m}^{2}$ ). As in the preceding cases, times-at-liberty $\left(t_{i}\right)$ and squared distance traveled $\left(\mathrm{d}^{2}{ }_{i}\right)$ were analyzed using the Bayesian approach described in 'Model parameterization' and Supplement 1. As in the other simulation experiments, this experiment was repeated 1000 times; thus, 1000 sets of estimated movement parameters were compared with the known values (i.e. those used for running the simulations).

\section{RESULTS}

\section{Mark-release-recapture program}

A total of 689 C. julis individuals were marked and released, and $34(4.9 \%)$ of these were recaptured in the period up to July 2010. For 2 of the fish returned, the described recapture location was very imprecise; these fish were therefore not included in the analysis. The maximum distance between any specific marking and recapture location was $448 \mathrm{~m}$, and the longest time elapsed between marking and recapture was $227 \mathrm{~d}$. The relationship between the distances and the time elapsed from marking to recapture is shown in Fig. 3.

The size of home range may be under-estimated if some fish move long distances and became unavailable to the recreational fishers. This scenario is highly implausible in our case because (1) recreational fishers are very active not only in suitable habitats (for Coris julis) but also in many others (including deeper waters); (2) Mallorca is an island, and a fish would have to move through hundreds of miles of open waters before finding other locations with suitable habitats; and (3) because the study was completed at Palma Bay (South of Mallorca), fish could conceivably move to other parts of the island; however, the communication program in the marking experiment covered 
the whole island. Moreover, fishing effort is large not only at Palma Bay but also all around the island (Morales-Nin et al. 2005), and fishers from other parts of the island have returned tagged fish (in other tagging experiments) of other species (Serranus scriba, Argyrosomus regius or Dentex dentex), but never of C. julis.

\section{Analysis of the observed data}

MCM chains for $k$ did not converge. The posterior distribution for $k$ was very close to the prior distribution. The wide posterior distribution of $k$ (and $\varepsilon$ ) made the estimates of these parameters too uncertain to be useful. However, the ratio $\varepsilon / k$ quickly converged (Gelman-Rubin convergence statistic as implemented in OpenBugs), and the range of the posterior distribution was very narrow in comparison with the prior distribution. The median value of $\varepsilon / k$ was 17290.0 . The $95 \%$ credibility interval $(\mathrm{CI})$ of $\varepsilon / k$ after convergence and thinning of 5 independent MCM chains was 12330.0 to $25210.0 \mathrm{~m}^{2}$.

The radius of the home range estimated using the Bayesian approach (Eq. 11) was $227.6 \mathrm{~m}$. The $2.5 \%$ and $97.5 \%$ Bayesian CI values were 192.2 and $274.8 \mathrm{~m}$, respectively.

\section{Reliability of parameter estimates with $\mathbf{n}=\mathbf{3 2}$ recaptures}

Simulation Expt 1 demonstrated that the Bayesian estimates determined using 32 randomly simulated recaptures were reasonably accurate and precise only for the ratio $\varepsilon / k$ (Table 1$)$. The mean of the estimates of $\varepsilon / k$ obtained from the 1000 sets of simulated data $\left(18192 \mathrm{~m}^{2}\right.$ ) was only slightly smaller than the true value $\left(20000 \mathrm{~m}^{2}\right)$. The averaged upper and lower limits of the $95 \%$ CI were 12949 to $29011 \mathrm{~m}^{2}$. The $95 \% \mathrm{CI}$ of the estimated $\varepsilon / k$ value included the true value $\left(20000 \mathrm{~m}^{2}\right)$ in $100 \%$ of the 1000 simulations. Similarly, the estimated radius of the home range was $232.2 \mathrm{~m}$, only slightly smaller than the true value $(244.8 \mathrm{~m})$. The averaged 95\% CIs ranged from 195.9 to $286.2 \mathrm{~m}$. In contrast, the estimates of $k(4895.9)$ and $\varepsilon\left(8.9 \times 10^{7}\right)$ were clearly biased and inaccurate (the true values were $k=0.1$ and $\varepsilon=2000$ ).

The results of Simulation Expt 1 also corroborated the expected asymptotic relationship between $<d^{2}(t)>$ (mean $d^{2}$ of 1000 fish for any specific $t$ ) and $t$ (the

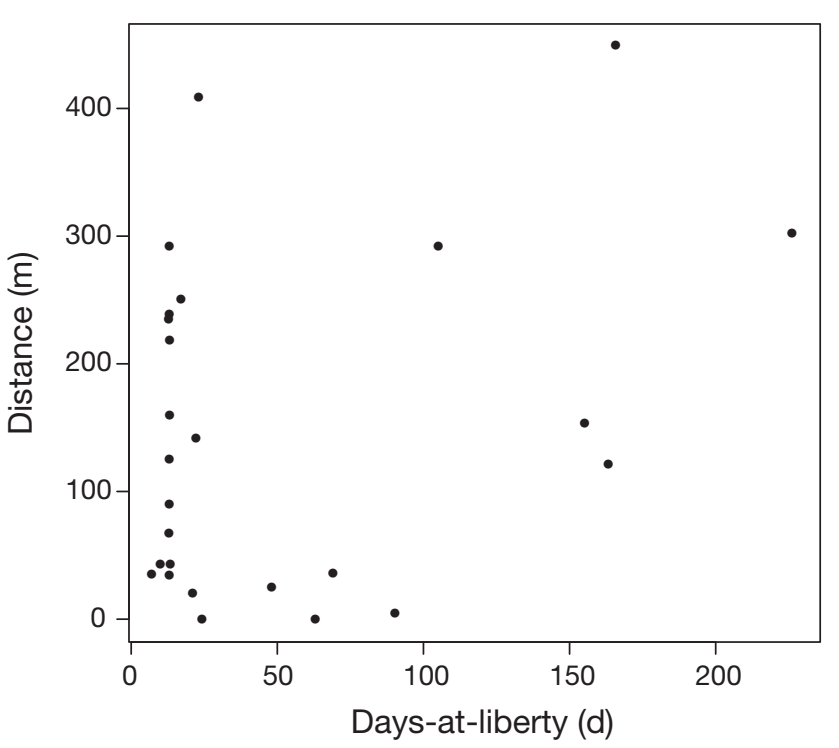

Fig. 3. Coris julis. Comparison between days-at-liberty and the distance between the mark and recapture locations

time elapsed between mark and recapture; Eq. 9, Fig. 4). The parameter $k$ corresponds to the slope of the curve before it reaches the asymptote. Thus, the biological interpretation of the model parameters is as follows: (1) $k$ is the rate (with dimension $\mathrm{T}^{-1}$ ) at which the fish explore the home range, (2) $\varepsilon\left(\mathrm{L}^{2} \mathrm{~T}^{-1}\right)$ measures how erratic the movement path is (tortuosity) and (3) $\varepsilon / k\left(\mathrm{~L}^{2}\right)$ is proportional to the size of the home range (Eq. 11).

\section{Relationship between precision and number of recaptures}

As expected, the larger the number of recaptures, the greater the precision and accuracy of the estimates. For $n=300$ simulated recaptures, the estimates for the parameters (mean $\pm \mathrm{SD}$ ) were $k=0.112 \pm 0.026$ (true

Table 1. Coris julis. Results of the 3 simulation experiments. Mean values $( \pm \mathrm{SD})$ of 1000 simulations for the radius $(\mathrm{m})$ of the home range. The 'true' radius value used for moving the fish in all simulation experiments was $244.8 \mathrm{~m}$. Expt $1 \mathrm{com}-$ pared the effect of number of recaptures. Results from Expts 2 and 3 should be compared to the first row of Expt 1. CI: averaged low and high limits of the $95 \%$ Bayesian credibility interval; Range: interval between these limits

\begin{tabular}{|c|c|c|c|c|}
\hline & $\mathrm{n}$ & Estimate & $\mathrm{CI}$ & Range \\
\hline \multicolumn{5}{|l|}{ Expt 1} \\
\hline Spatial homogeneity & 32 & $232.2( \pm 24.4)$ & 195.9 to 286.2 & 90.2 \\
\hline Spatial homogeneity & 300 & $244.1( \pm 8.9)$ & 228.0 to 263.1 & 35.0 \\
\hline \multicolumn{5}{|l|}{ Expt 2} \\
\hline Spatial heterogeneity & 15 to 46 & $230.4( \pm 29.4)$ & 192.0 to 299.0 & 107.0 \\
\hline \multicolumn{5}{|l|}{ Expt 3} \\
\hline Individual heterogeneity & 32 & $231.0( \pm 27.7)$ & 194.7 to 285.7 & 90.9 \\
\hline
\end{tabular}




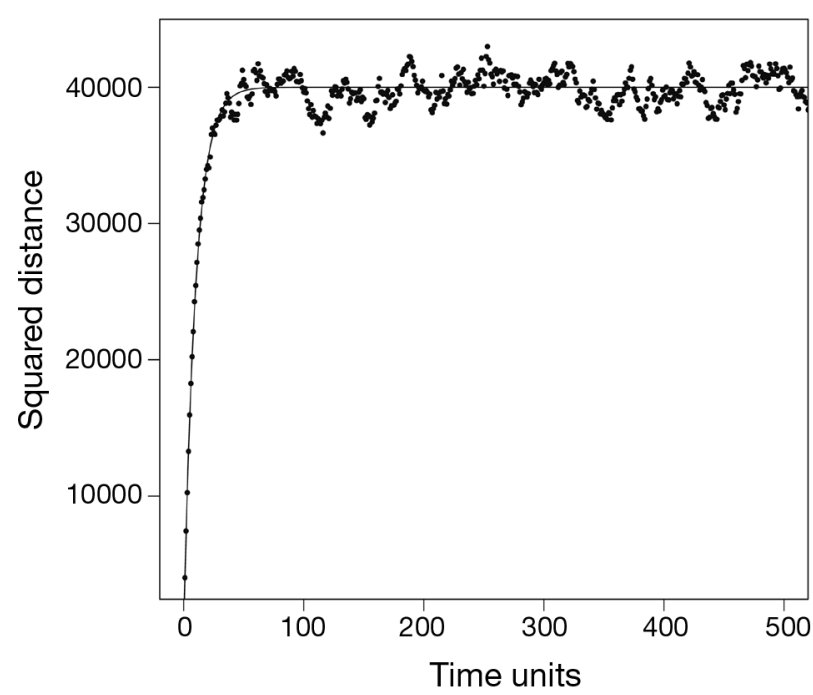

Fig. 4. Relationship between the mean distance travelled squared $\overline{d^{2}(t)}$ and $t$ (time steps) from 1000 simulated fish. Note that the line is not the fitted relationship but the expected one using Eq. (9)

value $=0.1), \varepsilon=2210.8 \pm 432.3$ (true value $=2000)$ and $\varepsilon / k=19924.1 \pm 1437.6$ (true value $=20000$ ). The $95 \%$ CI of the estimated $\varepsilon, k$ and $\varepsilon / k$ values included the true values in $100 \%$ of the 1000 simulations. Thus, when $\mathrm{n}$ is large, not only $\varepsilon / k$, but also $\varepsilon$ and $k$ are precisely and accurately estimated.

The mean estimate for the radius of the home range ( $244.1 \mathrm{~m}$; averaged $95 \%$ CIs were 228.0 to $263.1 \mathrm{~m}$ ) is very close to the true one $(244.8 \mathrm{~m})$. It is, however, also remarkable that the increased precision (measured as the averaged range of the 1000 simulated 95\% CIs) from 32 to 300 recaptured fish is reduced only from 90 to $35 \mathrm{~m}$ (Table 1). Despite a significant increase in the number of recaptures, precision is only 2.5 times better using 300 recaptured fish than 32.

\section{Effects of fishing effort spatial heterogeneity}

The size of the home range was estimated after releasing $N_{0}$ fishes with known movement parameters in a spatial scenario of heterogeneous fishing mortality. It is important to remember that the range of variability in fishing effort and the level of spatial autocorrelation were used to build simulated scenarios that emulate the current environment of Palma Bay. The whole simulation was repeated 1000 times. Note that the mean estimated value for the radius of the home range $(230.4 \mathrm{~m}$; Table 1 ; the $95 \% \mathrm{CI}$ of the estimated $\varepsilon / k$ value included the true value in $100 \%$ of the 1000 simulations) is very close not only to the true value (244.8 $\mathrm{m}$ ) but also to the estimated value when fishing mortality is assumed to be spatially constant (232.2 m). Moreover, the averaged range of the $95 \% \mathrm{CI}$ is comparable to the one obtained when fishing mortality is assumed to be spatially constant $(90.0$ to $107.0 \mathrm{~m}$; Table 1). Therefore, it should be concluded that, even if fishing effort in some specific localities of the spatial scenario is 10 times larger than the fishing effort experienced in other sites, this degree of spatial heterogeneity does not significantly affect the precision and accuracy of the estimated home range size.

\section{Effects of between-individual variability}

In Simulation Expt 3, the size of the home range was estimated from $n=32$ fishes that move in an isotropic spatial scenario. In this case, the movement parameters varied between individuals. Again, the averaged estimated value for the radius of the home range $(231.0 \mathrm{~m}$; Table 1 ; the $95 \%$ CI of the estimated $\varepsilon / k$ value included the true value in $100 \%$ of the 1000 simulations) is not only very close to the true value $(244.8 \mathrm{~m})$ but also to the estimated value when all fish are assumed to have the same movement parameters and to move in a spatially homogeneous scenario (232.2 m; Table 1). Moreover, the averaged range of the $95 \% \mathrm{CI}$ is comparable to the one obtained when it was assumed that all individuals have the same movement parameters (Table 1). Note that the between-individual variability in home range size emulates the variability described for a similar species. Therefore, it seems that a relatively small amount of between-individual variability does not significantly affect the precision and accuracy of the estimate of home range size.

\section{DISCUSSION}

The radius of the circular home range of Coris julis is surprisingly small $(227.6 \mathrm{~m})$. Nevertheless, the high site fidelity detected in $C$. julis is in agreement with studies on other species of the Labridae family. Using acoustic telemetry, previous studies have reported home ranges of 938 to $82070 \mathrm{~m}^{2}$ (radius = 16 to $162 \mathrm{~m}$ ) for Semicossyphus pulcher (Topping et al. 2005) and 300 to $2353 \mathrm{~m}^{2}$ (radius $=10$ to $27 \mathrm{~m}$ ) for Tautogolabrus adspersus (Bradbury et al. 1995). Using mark and recapture experiments, small home ranges have also been reported (areas of $100 \times 25 \mathrm{~m}$ or less) for the temperate labrids Notolabrus tetricus, Pictilabrus laticlavius, Pseudolabrus psittaculus and Notolabrus fucicola (Barrett 1995). Moreover, the home range of $C$. julis is similar to those of other similarly-sized species inhabiting Posidonia oceanica beds, such as Sarpa salpa, with home ranges ranging from 1596 to $285305 \mathrm{~m}^{2}$ (radius = 
23 to $301 \mathrm{~m}$ ) (Jadot et al. 2006); Serranus Scriba, with home ranges ranging from 7600 to $13330 \mathrm{~m}^{2}$ (radius $=$ 491 to $651 \mathrm{~m}$ ) (March et al. 2010); and Serranus cabrilla (Alós et al. 2011). Other small reef species, such as Chrysoblephus laticeps (Sparidae), also have small home ranges (from 1000 to $3000 \mathrm{~m}^{2}$; radius $=18$ to $31 \mathrm{~m}$; Kerwath et al. 2007a,b).

Coris julis is abundant and widespread along all the Palma Bay, where it finds a suitable habitat formed by large and continuous patches of Posidonia oceanica beds over rocky bottoms. Suitable areas are orders of magnitude larger than the size of the home range, and there are no obvious environmental barriers within patches. Thus, the case of $C$. julis and the increasing number of species for which small home range are reported (Botsford et al. 2009 and references above) seems to reject the null hypothesis that all fish freely move within large patches of suitable habitat. This free-moving pattern occurs when fish move within a homogeneous environment following random stimuli. However, in the case of small home range, there is a need for an additional behavioral rule for which each specific fish will tend to be attached to a very specific micro-site. The movement of $C$. julis is described here by a BRW process in a harmonic potential field whose strength describes the extent of the home range. The rationale behind this model is that the fish still moves within a homogeneous environment following random stimuli, but this rule is combined with a tendency to remain around a specific point. Therefore, an obvious implicit constraint to applying the methodological approach demonstrated here is that the patches of suitable habitat must be clearly larger than the putative home range. For example, the model proposed here is clearly unsuitable for pelagic or large predators moving at the oceanic scale (Block et al. 2005).

Concerning the estimation of the parameters of the movement model, the simulation experiments demonstrated that the analytic strategy is reasonably accurate and precise. The estimate for the radius of the home range with $n=300$ recaptures is unbiased and accurate (Table 1). Certainly, when $\mathrm{n}=32$, the radius of the home range is slightly underestimated, but the difference between the true and the estimated radius is only $12 \mathrm{~m}$. This deviation is not biologically relevant. Precision only increases 2.5 times when the number of recaptured fish is increased from 32 to 300. Thus, for most purposes, a relatively small number of recaptured fish could be sufficient to provide reasonably accurate and precise estimates of home range size.

Moreover, the estimation of home range size is robust against realistic departures from some of the implicit assumptions of the model. Specifically, home range size estimates are virtually the same when fishing effort is isotropic or spatially heterogeneous.
Similarly, the existence of some between-individual variability in movement parameters does not affect precision and accuracy of home range size estimates. Therefore, the method seems suitable for real-world applications, when (1) the number of recaptures is small and (2) spatial variability or between-individual heterogeneity is moderate.

When the objective is to estimate not only home range size but also $k$ and $\varepsilon$, the number of recaptured fish must be larger. In our case, the simulation experiments demonstrate that the estimates for these parameters are accurate and precise when $n=300$ recaptures. In addition, the simulation experiments corroborated the expected asymptotic relationship between $<d^{2}(t)>$ and $t$ (Fig. 4). More interestingly, we show not only how the ratio $\varepsilon / k$ is related to home range size, but also that the parameter $k$ itself determines the slope of the curve before the curve reaches the asymptote.

Accurate estimates of $k$ and $\varepsilon$ will be needed, for example, when the objective is to use the movement model to scale up from individual fish to the population level. For example, an individual-based model that includes adult fish movement rules has been used to predict the effects of an MPA on the abundance, age structure and spill-over of a Chrysoblephus laticeps (Sparidae) population (Kerwath et al. 2008). Further developments in the model proposed here will be needed before it can be used with these objectives. Specifically, the simple version of BRW presented here assumes that the strength of the potential field is constant in time and space. Spatio-temporal changes in the values of the movement parameters (e.g. those putatively related with resource availability, fish density or fishing effort) can be tested and modeled by expanding the model in Supplement 1 to a mixedeffects hierarchical model (Clark 2007). Similarly, shifts in the position of the home range center (Crook 2004) could be modeled with state-space models (Patterson et al. 2008). These approaches will require larger number of recaptured fish.

The combination of high site fidelity and small home range has a number of biologically relevant outcomes. One of the most obvious is that adult spillover from MPAs (Kramer \& Chapman 1999) will be significant only when the MPA is comparable to or larger than the home range. Thus, relatively small MPAs can be effective for preserving local adult stocks of Coris julis and similar species. This could be the case for the Cap Enderrocat Marine Reserve, located at Palma Bay. This MPA has an integral zone $\left(2 \mathrm{~km}^{2}\right.$; all fishing activity is prohibited) and a buffer zone $\left(24 \mathrm{~km}^{2}\right.$; commercial and recreational fishing are permitted, but with some management regulations). The combination of high site fidelity and small home range also justifies the use of 
C. julis or similar species as biomarkers of environmental quality (Sureda et al. 2006, Bonacci et al. 2007) because reduced mobility implies that a specific individual is subjected to uniform environmental conditions over a significant portion of its life span.

Acknowledgements. We thank A. M. Grau, A. Grau, S. Martino, B. Morales-Nin, I. Álvarez, M. Cabanellas, F. Cardona and all volunteer recreational anglers. The present study was financed by the ROQUER (CTM2005-00283) and CONFLICT (CGL2008-958) projects and funded by the Spanish Ministry of Research and Science; the ACOUSTIC TRACKING (UGIZC) research project was funded by the Govern de les Illes Balears. D.M. and J.A. had a fellowship supported by the Spanish Ministry of Research and Science. The present study was carried out with permission from the local fisheries administration, Direcció General de Pesca del Govern de les Illes Balears, for fish tagging at Palma Bay.

\section{LITERATURE CITED}

Alós J (2008) Influence of hooking injury, capture depth and venting on mortality of painted comber, Serranus scriba (Linnaeus, 1758), released by recreational anglers. ICES J Mar Sci 65:1620-1625

> Alós J, Palmer M, Grau AM, Deudero S (2008) Effects of hook size and barbless hooks on hooking injury, catch per unit effort and fish size in a mixed-species recreational fishery in the Western Mediterranean Sea. ICES J Mar Sci 65: 899-905

Alós J, Mateu-Vicens G, Palmer M, Grau AM, CabanellasReboredo M, Box A (2009) Performance of circle hooks in a mixed-species recreational fishery. J Appl Ichthyol 25: 565-570

> Alós J, March M, Palmer M, Grau A, Morales-Nin B (2011) Spatial and temporal patterns in Serranus cabrilla habitat use in the NW Mediterranean revealed by acoustic telemetry. Mar Ecol Prog Ser 427:173-188

Barrett NS (1995) Short- and long-term movement patterns of six temperate reef fishes (Families Labridae and Monacanthidae). Mar Freshw Res 46:853-860

Block BA, Teo SLH, Walli A, Boustany A and others (2005) Electronic tagging and population structure of Atlantic bluefin tuna. Nature 434:1121-1127

Bonacci S, Iacocca A, Fossi S, Lancini L, Caruso T, Corsi I, Focardi S (2007) Biomonitoring aquatic environmental quality in a marine protected area: A biomarker approach. Ambio 36:308-315

Botsford LW, Brumbaugh DR, Grimes C, Kellner JB and others (2009) Connectivity, sustainability, and yield: bridging the gap between conventional fisheries management and marine protected areas. Rev Fish Biol Fish 19:69-95

Bradbury C, Green JM, Bruce-Lockhart M (1995) Home ranges of female cunner, Tautogolabrus adspersus (Labridae), as determined by ultrasonic telemetry. Can J Zool 73: $1268-1279$

Calenge C (2006) The package 'adehabitat' for the R software: A tool for the analysis of space and habitat use by animals. Ecol Model 197:516-519

Clark JS (2007) Models for ecological data. Princeton University Press, Princeton, NJ

> Cocheret de la Morinière E, Pollux BJA, Nagelkerken I, van der Velde G (2002) Post-settlement life cycle migration patterns and habitat preference of coral reef fish that use seagrass and mangrove habitats as nurseries. Estuar Coast Shelf Sci 55:309-321

Codling EA, Plank MJ, Benhampu S (2008) Random walks models in biology. J R Soc Interface 5:813-834

Crook DA (2004) Is the home range concept compatible with the movements of two species of lowland river fish? J Anim Ecol 73:353-366

Gardiner CW (1990) Handbook of stochastic methods for physics, chemistry and the natural sciences. Springer, Berlin

> Heupel MR, Semmens JM, Hobday AJ (2006) Automated acoustic tracking of aquatic animals: scales, design and deployment of listening station arrays. Mar Freshw Res 57:1-13

Hilborn R (1990) Determination of fish movement patterns from tag recoveries using maximum likelihood estimators. Can J Fish Aquat Sci 47:635-643

> Horne JS, Garton EO, Krone SM, Lewis JS (2007) Analyzing animal movements using Brownian bridges. Ecology 88: 2354-2363

> Jadot C, Donnay A, Acolas ML, Cornet Y, Anras MLB (2006) Activity patterns, home-range size, and habitat utilization of Sarpa salpa (Teleostei: Sparidae) in the Mediterranean Sea. ICES J Mar Sci 63:128-139

Jonsen ID, Myers RA, Flemming JM (2003) Meta-analysis of animal movement using state-space models. Ecology 84: 3055-3063

Jonsen ID, Flemming JM, Myers RA (2005) Robust statespace modelling of animal movement data. Ecology 86: 2874-2880

Kerwath SE, Götz A, Attwood CG, Cowley PD, Saber WHH (2007a) Movement pattern and home range of Roman Chrysoblephus laticeps. S Afr J Mar Sci 29:93-103

Kerwath SE, Götz A, Attwood CG, Sauer WHH, Wilke CG (2007b) Area utilisation and activity patterns of roman Chrysoblephus laticeps (Sparidae) in a small marine protected area. S Afr J Mar Sci 29:259-270

Kerwath SE, Götz A, Attwood CG, Sauer WHH (2008) The effect of marine protected areas on an exploited population of sex-changing temperate reef fish: an individualbased model. S Afr J Mar Sci 30:337-350

Kramer DL, Chapman MR (1999) Implications of fish home range size and relocation for marine reserve function. Environ Biol Fish 55:65-79

Kristiansen T, Jorgensen C, Lough RG, Vikebo F, Fiksen O (2009) Modeling rule-based behavior: habitat selection and the growth-survival trade-off in larval cod. Behav Ecol 20:490-500

Lejeune P (1987) The effect of local stock density on social behaviour and sex change in the Mediterranean labrid Coris julis. Environ Biol Fish 18:135-141

> Linde M, Palmer M (2008) Testing Allsop and West's size at sex change invariant within a fish species: a spurious ratio or a useful group descriptor? J Evol Biol 21:914-917

March D (2008) Los SIG en la monitorización y modelado espacial de la pesca recreativa. IG+ 10:2-4

- March D, Palmer M, Alós J, Grau A, Cardona F (2010) Shortterm residence, home range size and diel patterns of the painted comber Serranus scriba in a temperate marine reserve. Mar Ecol Prog Ser 400:195-206

Marshall DJ, Monro K, Bode M, Keough MJ, Swearer WS (2010) Phenotype-environment mismatches reduce connectivity in the sea. Ecol Lett 13:128-140

> McGarvey R (2009) Methods of estimating mortality and movement rates from single-tag recovery data that are unbiased by tag non-reporting. Fish Sci 17:291-304

McGarvey R, Feenstra JE (2002) Estimating rates of fish 
movement from tag recoveries: conditioning by recapture. Can J Fish Aquat Sci 59:1054-1064

McGarvey R, Linnane AJ, Feenstra JE, Punt AE, Matthews JM (2010) Integrating recapture-conditioned movement estimation into spatial stock assessment: a South Australian lobster fishery application. Fish Res 105:80-90

Morales-Nin B, Moranta J, Garcia C, Tugores MP, Grau AM, Riera F, Cerda M (2005) The recreational fishery off Majorca Island (Western Mediterranean): Some implications for coastal resource management. ICES J Mar Sci 62: 727-739

Nagelkerken I, Dorenbosch M, Verberk WCEP, Cocheret de la Morinière E, van der Velde G (2000) Importance of shallow-water biotopes of a Caribbean bay for juvenile coral reef fishes: patterns in biotope association, community structure and spatial distribution. Mar Ecol Prog Ser 202: 175-192

Parada C, Mullon C, Roy C, Freon P, Hutchings L, van der Lingen CD (2008) Does vertical migratory behaviour retain fish larvae onshore in upwelling ecosystems? A modelling study of anchovy in the southern Benguela. Afr J Mar Sci 30:437-452

Parsons D, Egli D (2005) Fish movement in a temperate marine reserve: New insights through application of acoustic tracking. Mar Technol Soc J 39:56-63

Patterson TA, Thomas L, Wilcox C, Ovaskainen O, Matthiopoulos J (2008) State-space models of individual animal movement. Trends Ecol Evol 23:87-94

Royle JA, Nichols JD, Karanth KU, Gopalaswamy AM (2009) A hierarchical model for estimating density in camera-trap studies. J Appl Ecol 46:118-127

Sanchez-Delgado F (1981) Contribución al conocimiento de los lábridos (familia Labridae) de las costas ibéricas. Parte I: Descripción de las especies. Boletín del Instituto Español

Editorial responsibility: Hans Heinrich Janssen, Oldendorf/Luhe, Germany
Oceanografía 6:19-57

Santos MN, Monteiro CC, Lasserre G (2005) Observations and trends on the intra-annual variation of the fish assemblages on two artificial reefs in Algarve coastal waters (Southern Portugal). Sci Mar 69:415-426

Schlather M (2001) Simulation and analysis of random fields. R News 1:18-20 (available at http://cran.r-project.org/ doc/Rnews/)

Stergiou KI, Karpouzi VS (2002) Feeding habits and trophic levels of Mediterranean fish. Rev Fish Biol Fish 11: $217-254$

Sureda A, Box A, Enseñat M, Alou E, Tauler P, Deudero S, Pons A (2006) Enzymatic antioxidant response of a labrid fish (Coris julis) liver to environmental caulerpenyne. Comp Biochem Physiol C Toxicol Pharmacol 144:191-196

> Topping DT, Lowe CG, Caselle JE (2005) Home range and habitat utilization of adult California sheephead, Semicossyphus pulcher (Labridae), in a temperate no-take marine reserve. Mar Biol 147:301-311

Turchin P (1998) Quantitative analysis of movement: measuring and modeling population redistribution in animals and plants. Sinauer, Sunderland, MA

> Unsworth RKF, Wylie E, Smith DJ, Bell JJ (2007) Diel trophic structuring of seagrass bed fish assemblages in the Wakatobi Marine National Park, Indonesia. Estuar Coast Shelf Sci 72:81-88

> Vikebø F, Jørgensen C, Kristiansen T, Fiksen O (2007) Drift, growth, and survival of larval Northeast Arctic cod with simple rules of behaviour. Mar Ecol Prog Ser 347: 207-219

- Voegeli FA, Smale MJ, Webber DM, Andrade Y, O'Dor RK (2001) Ultrasonic telemetry, tracking and automated monitoring technology for sharks. Environ Biol Fish 60: $267-281$

Submitted: August 18, 2009; Accepted: February 28, 2011 Proofs received from author(s): May 12, 2011 